\title{
Penaksiran Parameter Regresi Linier Logistik dengan Metode Maksimum Likelihood Lokal pada Resiko Kanker Payudara di Makassar
}

\author{
Sutrianah Burhan ${ }^{1}$, Andi Kresna Jaya ${ }^{1}$
}

\begin{abstract}
Abstrak
Penelitian ini dilakukan untuk melihat hubungan resiko kanker terhadap usia wanita, jenis pendidikan dan pekerjaan di kota Makassar dengan menggunakan regresi logistik. Pada penaksiran parameternya digunakan metode local maximum likelihood yaitu penaksiran parameter dengan mempertimbangkan ukuran pemusatan datanya, seperti mean dan modusnya. Penaksiran parameternya kemudian menggunakan metode Newton-Rhapson.
\end{abstract}

Kata Kunci: Regresi logistik, metode local maximum likelihood, metode NewtonRhapson.

\section{Pendahuluan}

Sepanjang tahun 2011, beberapa pasien wanita memeriksakan diri ke rumah sakit di kota Makassar untuk mengetahui apakah menderita kanker payudara atau tidak [8]. Sebagaimana diketahui kanker payudara (Carcinoma mammae) adalah tumor ganas yang menyerang jaringan payudara, jaringan payudara tersebut terdiri dari kelenjar susu, saluran kelenjar dan jaringan penunjang payudara seperti lemak dan saraf. Data yang diperoleh menunjukkan bahwa umur pasien yang memeriksakan diri sangat bervariatif [3]. Jika kategori menderita kanker payudara atau tidak pada kasus ini dimisalkan sebagai peubah respon kategorik dan umur, tingkat pendidikan dan jenis pekerjaan adalah peubah-peubah penjelas, maka hubungan kedua variabel tersebut dapat dinyatakan sebagai model regresi logistik dengan pendekatan Generalized Linier Model (GLM).

Beberapa literatur telah banyak menjelaskan tentang GLM, seperti [5], dan [4] yang menyatakan bahwa GLM merupakan sebuah model regresi tanpa memenuhi asumsi seperti pada regresi linier klasik. Sementara [7] membahas tentang salah satu kasus dalam GLM adalah Regresi logistik. Peubah respon dalam regresi logistik ini berupa data yang bersifat kualitatif atau kategorik.

Berdasarkan hal ini, semua peubah respon yang bersifat kualitatif yang dimaksud dalam tulisan ini adalah yang hanya memiliki dua hasil yang mungkin. Contoh: sukses atau gagal, lulus atau tidak lulus, positif kanker atau tidak. Simbol yang biasanya digunakan yaitu dua buah bilangan 0 atau 1 untuk menggantikan kategori pada variabel respon sehingga dapat didekati dengan distribusi Bernoulli [2].

Analisis yang digunakan untuk membantu menyelesaikan masalah tersebut adalah model regresi logistik [7]. Regresi logistik biner digunakan ketika hanya ada dua kemungkinan variabel respon. Analisis regresi logistik biner bertujuan untuk memperoleh hubungan antara $X$ sebagai peubah penjelas dengan $Y$ sebagai peubah respon. Berapapun nilai $X$ bila disubtitusikan ke dalam fungsi logistik hasilnya akan berkisar antara 0 dan 1 . Untuk mengestimasi parameter dalam

\footnotetext{
${ }^{1}$ Jurusan Matematika FMIPA Universitas Hasanuddin, email: andikresna@yahoo.com
} 
regresi salah satu metode yang digunakan adalah metode local maximum likelihood [2], selanjutnya dinyatakan metode LML yang mempertimbangkan ukuran pemusatan data dalam mengestimasi parameternya. Sehingga untuk data kejadian kanker payudara di kota Makassar tahun 2011 terhadap umur dapat diasumsikan memenuhi bentuk regresi logistik biner dengan menggunakan metode LML mengacu pada rata-rata nilai data peubah-peubah penjelasnya atau modus datangnya pasien yang memeriksakan diri. Sampel yang dianalisis adalah data kejadian kanker payudara pada wanita di R.S. Bhayangkara Mappa Oddang, R.S. Pelamonia dan RSUP. Dr. Wahidin Sudirohusodo Makassar tahun 2011 dengan ukuran sampel 70.

\section{Landasan Teori}

\subsection{Percobaan Bernoulli}

Jika positif dan negatif menderita kanker payudara untuk seorang wanita diasumsikan memenuhi sebuah percobaan Bernoulli sehingga kemungkinan jika positif mempunyai peluang sebesar $p$ dan peluang kemungkinan negatif menderita kanker adalah $(1-p)$. Misalkan $Y$ adalah peubah acak yang terkait dengan percobaan Bernoulli dengan mendefinisikan sebagai berikut:

$$
Y(\text { positif kanker })=1 \text { dan } Y(\text { negatif kanker })=0 \text {, }
$$

Maka fungsi kepadatan peluang $Y$ dapat ditulis sebagai berikut:

$$
f(y)=p^{y}(1-p)^{1-y}, \quad y=0,1 \text {. }
$$

Rata-rata untuk $Y$ yang berdistribusi Bernoulli adalah

$$
\mu=E(Y)=\sum_{y=0}^{1} y p^{y}(1-p)^{1-y}=(0)(1-p)+(1)(p)=p,
$$

dan variansinya adalah

$$
\sigma^{2}=\operatorname{var}(Y)=\sum_{y=0}^{1}(y-p)^{2} p^{y}(1-p)^{1-y}=p(1-p) .
$$

Misalkan terdapat $n=70$ wanita yang memeriksakan diri ke rumah sakit diasumsikan berdistribusi Bernoulli, dan masing-masing mempunyai peluang positif kanker yang berbedabeda dan saling tidak mempengaruhi, katakanlah $p_{i}$ untuk $i=1,2, \cdots, 70$. Maka untuk setiap $i=1,2, \cdots, 70$ diperoleh $Y_{i}$ peubah acak yang saling bebas dan identik berdistribusi Bernoulli, dengan fungsi massa peluangnya adalah

$$
f\left(y_{i}\right)=p_{i}^{y_{i}}\left(1-p_{i}\right)^{1-y_{i}}, \quad y_{i}=0,1, \quad i=1,2, \cdots, 70 .
$$

\subsection{Regresi Logistik Biner}

Regresi logistik biner merupakan salah satu pendekatan model matematika yang digunakan untuk menganalisis hubungan beberapa faktor dengan sebuah variabel yang bersifat dikotomus (biner). Peubah acak yang memenuhi sifat tersebut, model probabilitas regresi logistik dengan peubah penjelas $(\boldsymbol{x})$ adalah umur $\left(x_{1}\right)$, tingkat pendidikan $\left(x_{2}\right)$ dan jenis pekerjaan $\left(x_{3}\right)$ dapat diformulasikan sebagai berikut:

$$
E(y \mid x)=\frac{\exp (g(\boldsymbol{x}))}{1+\exp (g(\boldsymbol{x}))}
$$




\section{Sutrianah Burhan, Andi Kresna Jaya}

Karena sebelumnya telah dinyatakan bahwa peubah acak $y$ berdistribusi Bernoulli, maka $E(y \mid x)$ merupakan nilai peluang yang bergantung pada nilai-nilaix, $E(y \mid x)=p(\boldsymbol{x})$. Misalkan fungsi $p(\boldsymbol{x})$ merupakan fungsi nonlinier terhadap $g(\boldsymbol{x})$ sehingga perlu dilakukan transformasi logit untuk memperoleh fungsi yang linier agar dapat dilihat hubungan antara variabel respon $(y)$ dengan variabel penjelas $(\boldsymbol{x})$. Bentuk logit dari $p(\boldsymbol{x})$ dinyatakan sebagai:

$$
g(\boldsymbol{x})=\ln \left(\frac{p(\boldsymbol{x})}{1-p(\boldsymbol{x})}\right)
$$

Misalkan $\boldsymbol{x}=\left(x_{1}, x_{2}, x_{3}\right)$ dan $g(\boldsymbol{x})=\gamma_{0}+\gamma_{1} x_{1}+\gamma_{2} x_{2}+\gamma_{3} x_{3}$, maka diperoleh model regresi logistik yang dapat dituliskan dalam bentuk

$$
p(\boldsymbol{x})=E(y \mid \boldsymbol{x})=\frac{\exp \left(\gamma_{0}+\gamma_{1} x_{1}+\gamma_{2} x_{2}+\gamma_{3} x_{3}\right)}{1+\exp \left(\gamma_{0}+\gamma_{1} x_{1}+\gamma_{2} x_{2}+\gamma_{3} x_{3}\right)} .
$$

Karena setiap pengamatan untuk $n$ pasien diasumsikan saling bebas maka fungsi likelihood-nya merupakan perkalian antara masing-masing fungsi padat peluang $f\left(y_{i} ; p_{i}\right)$, yaitu:

$$
L\left(p_{i} \mid y_{1}, y_{2}, \cdots, y_{n}\right)=\prod_{i=1}^{n} p_{i}^{y_{i}}\left(1-p_{i}\right)^{1-y_{i}}
$$

Maka dengan mensubstitusi $p_{i}=p\left(\boldsymbol{x}_{i}\right)$ dengan menggunakan persamaan (1) diperoleh fungsi likelihood terhadap parameter-parameter $\gamma_{0}, \gamma_{1}$, dan $\gamma_{2}$ dari persamaan (2) menjadi:

$$
L\left(\gamma_{0}, \gamma_{1}, \gamma_{2}, \gamma_{3}\right)=\prod_{i=1}^{n} \frac{\exp \left(\gamma_{0} y_{i}+\gamma_{1} x_{1 i} y_{i}+\gamma_{2} x_{2 i} y_{i}+\gamma_{3} x_{3 i} y_{i}\right)}{\left(1+\exp \left(\gamma_{0}+\gamma_{1} x_{1 i}+\gamma_{2} x_{2 i}+\gamma_{3} x_{3 i}\right)\right)}
$$

\subsection{Metode Newton-Raphson}

Nilai parameter $\gamma$ dapat diperoleh dengan memaksimumkan fungsi likelihood-nya. Hal tersebut dilakukan dengan metode turunan pertama fungsi likelihood-nya terhadap setiap parameter yang disamakan dengan nol. Terkadang sulit menemukan turunan dari fungsi likelihood-nya sehingga yang dilakukan adalah menemukan nilai maksimum dari logaritma natural fungsi likelihood tersebut atau fungsi log-likelihood.

Fungsi log-likelihood adalah bentuk logaritma dari fungsi likelihood, yang dituliskan dalam bentuk:

$$
\ln L\left(p_{i} \mid y_{1}, y_{2}, \cdots, y_{n}\right)=\sum_{i=1}^{n} \ln \left(p_{i} y_{i}\left(1-p_{i}\right)^{1-y_{i}}\right)
$$

Berikut langkah-langkah dalam menentukan penduga parameter dengan metode Maximum Likelihood Estimation:

1. Menentukan fungsi likelihood

$$
L\left(p_{i} \mid y_{1}, y_{2}, \cdots, y_{n}\right)=\prod_{i=1}^{n} p_{i}^{y_{i}}\left(1-p_{i}\right)^{1-y_{i}}
$$

2. Menentukan fungsi log-likelihood 


\section{Sutrianah Burhan, Andi Kresna Jaya}

$$
\ln L\left(p_{i} \mid y_{1}, y_{2}, \cdots, y_{n}\right)=\sum_{i=1}^{n} \ln p_{i}^{y_{i}}\left(1-p_{i}\right)^{1-y_{i}}
$$

3. Memaksimumkan fungsi log-likelihood

Memaksimumkan fungsi log-likelihood untuk memperoleh nilai $\hat{\gamma}$ dapat dilakukan dengan langkah-langkah berikut:

a) Nilai $\hat{\gamma}$ diperoleh dari turunan pertama dengan disamadengankan nol

$$
\left.\frac{\partial l}{\partial \beta}\right|_{\gamma=\widehat{\gamma}}=0
$$

b) $\quad$ Nilai $\hat{\gamma}$ dikatakan memaksimumkan $L(\gamma)$ jika

$$
\left.\frac{\partial^{2} l}{\partial^{2} \gamma}\right|_{\gamma=\widehat{\gamma}}<0
$$

4. Menyelesaikan fungsi log-likelihood yang diperoleh pada langkah 2 atau 3 dan mendapatkan $\hat{\gamma}$ sebagai estimator Maximum Likelihood Estimation.

Apabila langkah menaksir parameter menggunakan metode Maximum Likelihood Estimation menghasilkan fungsi log-likelihood yang non-linier atau fungsi yang implisit sehingga sulit menyatakannya secara eksplisit, maka untuk mendapatkan penaksir parameter sebagai penyelesaian fungsi digunakan menggunakan metode Newton-Raphson [4]. Metode ini merupakan metode perhitungan yang iteratif, sehingga akan lebih mudah dikerjakan dengan bantuan komputer.

Metode Newton-Raphson didasarkan pada deret Taylor sebagai berikut:

$$
f\left(x_{t+1}\right)=f\left(x_{t}\right)+f^{\prime}\left(x_{t}\right)\left(x_{t+1}-x_{t}\right)+\cdots+\frac{f^{n}\left(x_{t}\right)}{n !}\left(x_{t+1}-x_{t}\right)^{n}
$$

Fungsi log-likelihood dengan parameter $\gamma$ dapat diselesaikan sehingga diperoleh nilai $\hat{\gamma}$ taksiran dengan menggunakan metode Newton-Raphson. Rumus penaksiran parameter $\hat{\gamma}$ pada iterasi ke- $(t+1)$ dalam proses iterasi $(t=0,1,2, \cdots)$ adalah sebagai berikut:

$$
\hat{\gamma}_{t+1}=\hat{\gamma}_{t}-\boldsymbol{D}\left(\gamma_{t}\right)^{-1} \boldsymbol{d}\left(\gamma_{t}\right)
$$

dengan

$$
\begin{array}{ll}
\hat{\gamma}_{t+1} & : \text { parameter taksiran } \gamma \text { pada iterasi ke- }(t+1) \\
\hat{\gamma}_{t} & : \text { parameter taksiran } \gamma \text { pada iterasi ke- }(t) \\
\boldsymbol{d}\left(\gamma_{t}\right) & \text { :turunan pertama fungsi likelihood } \\
\boldsymbol{D}\left(\gamma_{t}\right) & \text { :turunan kedua fungsi likelihood. }
\end{array}
$$

\section{Metode Local Maximum Likelihood}

Untuk kasus ini sebagaimana diuraikan pada bagian 1 dari paper ini, metode yang digunakan adalah metode LML. Fungsi likelihood yang digunakan adalah fungsi likelihood yang mempertimbangkan ukuran pemusatan peubah bebas $x$. Dalam hal ini metode LML dilanjutkan dengan metode Newton-Rhapson untuk mendapatkan penaksiran parameter model. Misalkan 


\section{Sutrianah Burhan, Andi Kresna Jaya}

bahwa ukuran pemusatan data pasien wanita dinyatakan sebagai $\bar{x}_{j}$, maka fungsi likelihood pada persamaan (3) menjadi

$$
L\left(\gamma_{0}, \gamma_{1}, \gamma_{2}, \gamma_{3}\right)=\prod_{i=1}^{n} \frac{\exp \left(\gamma_{0} y_{i}+\sum_{j=1}^{3} \gamma_{j}\left(x_{j i}-\bar{x}_{j}\right) y_{i}\right)}{\left(1+\exp \left(\gamma_{0} y_{i}+\sum_{j=1}^{3} \gamma_{j}\left(x_{j i}-\bar{x}_{j}\right)\right)\right)}
$$

Bentuk log-likelihood persamaan (5) untuk $\gamma=\gamma_{0}, \gamma_{1}, \gamma_{2}, \gamma_{3}$, dinyatakan dalam bentuk

$$
\begin{aligned}
\ln L(\boldsymbol{\gamma}) & =\ln \left(\prod_{i=1}^{n} \frac{\exp \left(\gamma_{0} y_{i}+y_{i} \sum_{j=1}^{3} \gamma_{j}\left(x_{j i}-\bar{x}_{j}\right)\right)}{1+\exp \left(\gamma_{0}+\sum_{j=1}^{3} \gamma_{j}\left(x_{j i}-\bar{x}_{j}\right)\right)}\right) \\
& =\sum_{i=1}^{n}\left(\ln \left(\frac{\exp \left(\gamma_{0} y_{i}+y_{i} \sum_{j=1}^{3} \gamma_{j}\left(x_{j i}-\bar{x}_{j}\right)\right)}{1+\exp \left(\gamma_{0}+\sum_{j=1}^{3} \gamma_{j}\left(x_{j i}-\bar{x}_{j}\right)\right)}\right)\right) .
\end{aligned}
$$

Untuk lebih memusatkan nilai penaksiran maka kita mengalikan dengan fungsi kernel $(K)$

dengan bandwidth $(h=1), K(\boldsymbol{x}-\overline{\boldsymbol{x}})=\frac{\sqrt{\sum_{j=1}^{3}\left(x_{j i}-\bar{x}_{j}\right)^{2}}}{J\left(\sqrt{\sum_{j=1}^{3}\left(x_{i j}-x_{j}\right)^{2}}\right)}$ dimana $J\left(\sqrt{\sum_{j=1}^{3}\left(x_{i j}-x_{j}\right)^{2}}\right)$ adalah jangkauan nilai $\left(\sqrt{\sum_{j=1}^{k}\left(x_{i j}-x_{j}\right)^{2}}\right)$ untuk $i=1,2, \cdots, n$.

Bentuk persamaan (6) yang dimodifikasi adalah

$$
\begin{aligned}
l=\ln L(\boldsymbol{\gamma})^{*}= & \sum_{i=1}^{n} y_{i}\left(\gamma_{0}+\sum_{j=1}^{3} \gamma_{j}\left(x_{j i}-\bar{x}_{j}\right)\right) K\left(\boldsymbol{x}_{\boldsymbol{i}}-\overline{\boldsymbol{x}}_{\boldsymbol{i}}\right) \\
& -\sum_{i=1}^{n} \ln \left(1+\exp \left(\gamma_{0}+\sum_{j=1}^{3} \gamma_{j}\left(x_{j i}-\bar{x}_{j}\right)\right)\right) K\left(\boldsymbol{x}_{\boldsymbol{i}}-\overline{\boldsymbol{x}}_{\boldsymbol{i}}\right)
\end{aligned}
$$

Kemudian persamaan (7) diturunkan terhadap parameter-parameternya.

Turunan terhadap $\gamma_{0}$,

$$
\frac{\partial l}{\partial \gamma_{0}}=\sum_{i=1}^{n}\left(y_{i}-\frac{\exp \left(\gamma_{0}+\sum_{j=1}^{3} \gamma_{j}\left(x_{j i}-\bar{x}_{j}\right)\right)}{1+\exp \left(\gamma_{0}+\sum_{j=1}^{3} \gamma_{j}\left(x_{j i}-\bar{x}_{j}\right)\right)}\right) K\left(\boldsymbol{x}_{\boldsymbol{i}}-\overline{\boldsymbol{x}}_{\boldsymbol{i}}\right)
$$

Turunan terhadap $\gamma_{j}$, untuk $j=1,2,3$ 


\section{Sutrianah Burhan, Andi Kresna Jaya}

$$
\frac{\partial l}{\partial \gamma_{j}}=\sum_{i=1}^{n}\left(y_{i}-\frac{\exp \left(\gamma_{0}+\sum_{j=1}^{3} \gamma_{j}\left(x_{j i}-\bar{x}_{j}\right)\right)}{1+\exp \left(\gamma_{0}+\sum_{j=1}^{3} \gamma_{j}\left(x_{j i}-\bar{x}_{j}\right)\right)}\right)\left(x_{j i}-\bar{x}_{j}\right) K\left(\boldsymbol{x}_{\boldsymbol{i}}-\overline{\boldsymbol{x}}_{\boldsymbol{i}}\right)
$$

Turunan kedua untuk persamaan (7) yang didasarkan pada turunan pertama dari persamaan (8) dan (9) untuk $m, k=1,2,3$. Kemudian, turunan kedua untuk $m \neq k$ adalah

$\frac{\partial^{2} l}{\partial \gamma_{m} \partial \gamma_{k}}=\sum_{i=1}^{n}-\left(x_{m i}-\bar{x}_{m}\right)\left(x_{k i}-\bar{x}_{k}\right) K\left(\boldsymbol{x}_{i}-\overline{\boldsymbol{x}}_{\boldsymbol{i}}\right) \times\left(\frac{\exp \left(\gamma_{0}+\sum_{j=1}^{3} \gamma_{j}\left(x_{j i}-\bar{x}_{j}\right)\right)}{\left(1+\exp \left(\gamma_{0}+\sum_{j=1}^{3} \gamma_{j}\left(x_{j i}-\bar{x}_{j}\right)\right)\right)^{2}}\right)$

Sedangkan untuk $\gamma_{0}$ turunan keduanya adalah

$$
\frac{\partial^{2} l}{\partial \gamma_{0}^{2}}=\sum_{i=1}^{n}-K\left(\boldsymbol{x}_{\boldsymbol{i}}-\overline{\boldsymbol{x}}_{\boldsymbol{i}}\right) \times\left(\frac{\exp \left(\gamma_{0}+\sum_{j=1}^{3} \gamma_{j}\left(x_{j i}-\bar{x}_{j}\right)\right)}{\left(1+\exp \left(\gamma_{0}+\sum_{j=1}^{3} \gamma_{j}\left(x_{j i}-\bar{x}_{j}\right)\right)^{2}\right.}\right),
$$

dan turunan pertama terhadap persamaan (8) terhadap $\gamma_{k}, k=1,2,3$ adalah

$$
\frac{\partial^{2} l}{\partial \gamma_{k} \partial \gamma_{0}}=\sum_{i=1}^{n}-\left(x_{k i}-\bar{x}_{k}\right) K\left(\boldsymbol{x}_{\boldsymbol{i}}-\overline{\boldsymbol{x}}_{\boldsymbol{i}}\right) \times\left(\frac{\exp \left(\gamma_{0}+\sum_{j=1}^{3} \gamma_{j}\left(x_{j i}-\bar{x}_{j}\right)\right)}{\left(1+\exp \left(\gamma_{0}+\sum_{j=1}^{3} \gamma_{j}\left(x_{j i}-\bar{x}_{j}\right)\right)\right)^{2}}\right)
$$

Perhitungan nilai-nilai dari $\gamma_{j} ; j=0,1,2,3$, kemudian dilakukan dengan metode NewtonRaphson yang ditunjukkan pada persamaan (4) dengan menggunakan bantuan Ms.Excel, dengan menggunakan dua ukuran pemusatan data, yaitu mean dan modus. Perhitungan juga dikombinasikan dengan dua nilai awal yang berbeda, yaitu dengan nilai awal $\gamma_{0}=\gamma_{1}=\gamma_{2}=$ $\gamma_{3}=0$, dan nilai-nilai $\gamma_{0}, \gamma_{1}, \gamma_{2}, \gamma_{3}$ yang diperoleh dari metode Ordinary Least Square.

\section{Hasil dan Pembahasan}

Persamaan (4) yang diperoleh sesuai dengan bentuk-bentuk yang sesuai dari persamaan (5) sampai (12) adalah

$$
\left(\begin{array}{l}
\gamma_{0} \\
\gamma_{1} \\
\gamma_{2} \\
\gamma_{3}
\end{array}\right)_{t+1}=\left(\begin{array}{l}
\gamma_{0} \\
\gamma_{1} \\
\gamma_{2} \\
\gamma_{3}
\end{array}\right)_{t}-\left(\begin{array}{cccc}
\frac{\partial^{2} l}{\partial \gamma_{0}^{2}} & \frac{\partial^{2} l}{\partial \gamma_{0} \partial \gamma_{1}} & \frac{\partial^{2} l}{\partial \gamma_{0} \partial \gamma_{2}} & \frac{\partial^{2} l}{\partial \gamma_{0} \partial \gamma_{3}} \\
\frac{\partial^{2} l}{\partial \gamma_{0} \partial \gamma_{1}} & \frac{\partial^{2} l}{\partial \gamma_{1}^{2}} & \frac{\partial^{2} l}{\partial \gamma_{1} \partial \gamma_{2}} & \frac{\partial^{2} l}{\partial \gamma_{1} \partial \gamma_{3}} \\
\frac{\partial^{2} l}{\partial \gamma_{0} \partial \gamma_{2}} & \frac{\partial^{2} l}{\partial \gamma_{1} \partial \gamma_{2}} & \frac{\partial^{2} l}{\partial \gamma_{2}^{2}} & \frac{\partial^{2} l}{\partial \gamma_{2} \partial \gamma_{3}} \\
\frac{\partial^{2} l}{\partial \gamma_{0} \partial \gamma_{3}} & \frac{\partial^{2} l}{\partial \gamma_{1} \partial \gamma_{3}} & \frac{\partial^{2} l}{\partial \gamma_{2} \partial \gamma_{3}} & \frac{\partial^{2} l}{\partial \gamma_{3}^{2}}
\end{array}\right)^{-1}\left(\begin{array}{c}
\frac{\partial l}{\partial \gamma_{0}} \\
\frac{\partial l}{\partial \gamma_{1}} \\
\frac{\partial l}{\partial \gamma_{2}} \\
\frac{\partial l}{\partial \gamma_{3}}
\end{array}\right) .
$$

Pengolahan dengan metode Newton-Rhapson dengan nilai awal $\gamma_{0}=\gamma_{1}=\gamma_{2}=\gamma_{3}=0$ diperoleh nilai-nilai penaksiran parameternya konvergen setelah iterasi ketujuh, diperoleh 


$$
\left(\begin{array}{l}
\gamma_{0} \\
\gamma_{1} \\
\gamma_{2} \\
\gamma_{3}
\end{array}\right)=\left(\begin{array}{c}
0.588 \\
0.0012 \\
0.3206 \\
1.157
\end{array}\right)
$$

Sedangkan dengan menggunakan nilai awal dari metode ordinary least square, nilai-nilai parameternya akan konvergen ke nilai yang sama dengan iterasi kelima. Hal yang sama juga diperoleh dengan mengganti ukuran pemusatan dari mean ke modus, bahkan median data.

Melalui uji kelayakan model yang telah dilakukan terhadap penaksiran parameter yang diperoleh untuk resiko kanker bagi wanita di kota Makassar, maka diperoleh bentuk regresi logistiknya adalah

$$
\bar{y}=\frac{\exp \left(0,5880+0,0012\left(x_{1}-\bar{x}_{1}\right)+0.3206\left(x_{2}-\bar{x}_{2}\right)+1.157\left(x_{3}-\bar{x}_{3}\right)\right)}{1+\exp \left(0,5880+0,0012\left(x_{1}-\bar{x}_{1}\right)+0.3206\left(x_{2}-\bar{x}_{2}\right)+1.157\left(x_{3}-\bar{x}_{3}\right)\right)} .
$$

\section{Daftar Pustaka}

[1] Agresti A., 1990. Categorical Data Analysis. John Wiley \& Sons., New York.

[2] Hogg R.V. et al., 2005. Introduction to Mathematical Statistics, $6^{\text {th }}$ edition. Prentice Hall Inc., USA.

[3] Burhan S., 2012. Penaksiran Parameter Regresi Logistik dengan Metode Local Maximum Likelihood. Skripsi. Universitas Hasanuddin, Makassar.

[4] Jong P. D. and Heller G. Z., 2008. Generalized Linear Models for Insurance Data. Cambridge University Press, Cambridge.

[5] McCullagh P. and Nelder J. A., 1989. Generalized Linear Models. Chapman \& Hall, London.

[6] Rencher A.C., 2000. Linear Model in Statistics. John Wiley \& Sons Inc., New York.

[7] Santos J. and Neves M., 2005. A Semiparametric Framework for The Generalized Linear Model: The Logistic Regression Case. Jurnal ISA/Technical, University of Lisbon.

[8] Syam A.D.P., 2011. Analisis Determinan Kanker Payudara pada Wanita di RS. Bhayangkara Mappa Oddang, RS. Pelamonia dan RSUP. Dr. Wahidin Sudirohusodo Makassar Tahun 2011. Tesis. Jurusan Epidemologi, FKM, Universitas Hasanuddin, Makassar.

[9] Tiro M. A., 2000. Analisis Regresi dan Korelasi. State University of Makassar Press, Makassar.

[10] Walpole R.E., and Myres R.H., 1995. Ilmu Peluang dan Statistika untuk Insinyur dan Ilmuwan, Edisi ke-4 (terjemahan). Penerbit ITB, Bandung. 